\title{
Survei Cross-Sectional Online Untuk Menilai Vaksin Covid-19 Terkait Akseptabilitas, Pengetahuan dan Kesediaan Membayar di Kalangan Mahasiswa Kesehatan Masyarakat di Provinsi Sumatera Utara
}

\author{
Daniel Ginting ${ }^{1 *}$, Nina Fentiana ${ }^{1}$, Rahmat Alyakin Dachi ${ }^{2}$ \\ ${ }^{1}$ Universitas Sari Mutiara Indonesia, Jalan Kapten Muslim No 79 Medan \\ ${ }^{2}$ Pascasarjana Kesehatan Masyarakat, Universitas Sari Mutiara Indonesia, Jalan Kapten Muslim No 79 Medan \\ *Correspondence email: dginting60@gmail.com
}

\begin{abstract}
Abstrak. Tujuan studi adalah menilai vaksin Covid-19 terkait akseptibilitas, pengetahuan dan kesediaan membayar di kalangan mahasiswa kesehatan masyarakat di Provinsi Sumatera Utara. Desain penelitian ialah survei cross sectional online menggunakan "Google Form" dengan sampel seluruh mahasiswa kesehatan masyarakat di Universitas Sari Mutiara Indonesia dan Universitas Prima Indonesia yang belum menerima vaksin Covid-19 (91 responden). Studi menemukan akseptabilitas vaksin Covid-19 di kalangan mahasiswa kesehatan masyarakat di Provinsi Sumatera Utara masih rendah $(46,2 \%)$ demikian juga kesediaan membayar $(36,3 \%)$. Tidak ada hubungan pengetahuan dengan akseptabilitas vaksin Covid-19. Mayoritas mahasiswa kesehatan masyarakat menganggap vaksin adalah obat untuk penyakit Covid-19. Ada hubungan yang signifikan antara kesediaan membayar dengan akseptabilitas vaksin Covid-19 pada mahasiswa kesehatan masyarakat, sehingga program vaksin gratis sangat menentukan tingkat cakupan vaksinasi Covid-19. Intervensi kampanye pendidikan kesehatan tentang vaksin Covid-19 dari ahli kesehatan masyarakat sangat diperlukan guna meluruskan pengetahuan vaksin Covid-19 mahasiswa yang akhirnya diharapkan mampu membangun kepercayaan terhadap efekstivitas vaksin Covid-19.
\end{abstract}

Kata kunci: Covid-19; kesehatan masyarakat; pengetahuan; vaksin

\begin{abstract}
The purpose of the study was to assess the Covid-19 vaccine related to acceptability, knowledge and willingness to pay among public health students in North Sumatra Province. The research design is an online cross-sectional survey using "Google Form" with a sample of all public health students at Sari Mutiara Indonesia University and Prima Indonesia University who have not received the Covid-19 vaccine (91 respondents). The study found that the acceptability of the Covid-19 vaccine among public health students in North Sumatra Province was still low (46.2\%) as was the willingness to pay (36.3\%). There is no relationship between knowledge and acceptability of the Covid-19 vaccine. The majority of public health students think vaccines are a cure for COVID-19. There is a significant relationship between willingness to pay and the acceptability of the Covid-19 vaccine for public health students, so the free vaccine program will determine the level of coverage of the Covid-19 vaccination. Health education campaign interventions about the Covid-19 vaccine from public health experts are needed to straighten students' knowledge of the Covid-19 vaccine, which is ultimately expected to be able to build confidence in the effectiveness of the Covid-19 vaccine.
\end{abstract}

Keywords: Covid-19; public health; knowledge; vaccine

\section{PENDAHULUAN}

Coronavirus Disease 2019 (Covid-19) yang disebabkan oleh Severe Acute Respiratory Syndrome Coronavirus 2 (SARS-CoV-2) masih menjadi ancaman global dengan 201.063.706 kasus dan 4.271.347 kematian tercatat pada 5 Agustus 2021 dimana 63.145.642 kasus tercatat di Asia dengan total kematian 915.042. Jumlah penambahan kasus per hari di Asia terus meningkat dari 10.531 per tanggal 16 Mei 2021 menjadi 73.154 per tanggal 5 Agustus 2021. Dari jumlah global ini Indonesia telah melaporkan 3.532.567 kasus dan 100.636 kematian (Worldometer, 2021). Sejumlah studi melaporkan vaksinasi berpotensi mengurangi dampak pandemik Covid-19 dalam hal penularan, kematian dan rawat inap (Jaklevic, 2020). Studi kohort retrospektif di Itali menunjukkan vaksinasi mampu menurunkan jumlah penduduk yang terinfeksi Covid-19 (Flacco et al., 2021).

Vaksin Covid-19 telah beredar diawal tahun 2021, tetapi keraguan muncul di sejumlah kalangan sehingga tingkat penerimaan vaksin Covid-19 masih rendah. Cakupan vaksinasi Covid-19 di Indonesia per tanggal 3 Agustus 2021 adalah 23,45\% (dosis 1) dan 10,66\% (dosesi 2) dengan sasaran vaksinasi adalah tenaga kesehatan, lanjut usia, petugas publik, masyarakat rentan dan masyarakat umum, serta penduduk usia 12-17 tahun). Di Propinsi Sumatera Utara cakupan vaksinasi dosis 1 adalah $16,37 \%$ dan dosis 2 sebesar 9,22\% (Kemenkes RI, 2021).

Studi di Ethiopia Selatan melaporkan status Pendidikan secara signifikans berhubungan dengan penerimaan vaksin Covid-19 (Mesele, 2021), pengetahuan mengenai Covid-19 juga dilaporkan berhubungan dengan penerimaan vaksin Covid-19 di (Bono et al., 2021). Cross sectional online di Perancis menunjukkan pengetahuan mengenai vaksin konvensional dan vaksin Covid-19 berhubungan dengan penerimaan vaksin di kalangan pelajar di tingkat universitas (Tavolacci et al., 2021). 
Daniel Ginting et al., Survei Cross-Sectional Online Untuk Menilai Vaksin Covid-19 Terkait Akseptabilitas, Pengetahuan dan Kesediaan Membayar di Kalangan Mahasiswa Kesehatan Masyarakat di Provinsi Sumatera Utara

Survei penerimaan vaksin Covid-19 di Indonesia mencatat masyarakat Indonesia mempunyai tingkat kepercayaan yang berbeda-beda terhadap vaksin Covid19 karena keterbatasan informasi mengenai jenis vaksin dan keamannanya. Provinsi Sumatera Utara adalah salah satu provinsi dengan tingkat penerimaan vaksin Covid19 lebih rendah dibandingkan dengan beberapa propinsi di Pulau Sumatera (Kementerian Kesehatan Republik Indonesia et al., 2020). Studi ini bertujuan untuk menilai vaksin Covid-19 terkait akseptabilitas, pengetahuan dan kesediaan membayar di kalangan mahasiswa kesehatan masyarakat di Provinsi Sumatera Utara.

\section{METODE}

Desain penelitian adalah cross sectional online menggunakan "Google Form" untuk menilai vaksin Covid-19 di kalangan mahasiswa kesehatan masyarakat di Provinsi Sumatera Utara. Data dikumpulkan dari Universitas Sari Mutiara Indonesia dan Universitas Prima Indonesia di Kota Medan sejak 28 Mei hingga 28 Juni 2021.

Kuesioner yang digunakan diperoleh dari "Survei Penerimaan Vaksin Covid-19 di Indonesia" yang dikembangkan oleh Kementerian Kesehatan Indonesia, WHO dan Unicef pada November 2020 (Kementerian Kesehatan Republik Indonesia et al., 2020). Sampel penelitian adalah seluruh mahasiswa kesehatan masyarakat di Universitas Sari Mutiara Indonesia dan Universitas Prima Indonesia yang belum menerima vaksin Covid-19. Penelitian berhasil mengumpulkan data dari 91 responden.

Seluruh data yang terkumpul di input ke Microsoft Excel selanjutnya dilakukan proses cleaning. Analisis statistik diskriptif dilakukan dengan tabel frekuensi, dan untuk umur disajikan dengan nilai minimal dan maksimal. Uji chisquare digunakan untuk melihat hubungan pengetahuan tentang vaksin Covid-19 dan kemauan membayar dengan penerimaan vaksin Covid19 menggunakan alfa 5\% (p-value 0,05).

\section{HASIL DAN PEMBAHASAN}

Penelitian mengumpulkan data dari 91 responden dari 2 universitas swasta yang memiliki program studi kesehatan masyarakat di Kota Medan, Provinsi Sumatera Utara. Mayoritas responden berjenis kelamian perempuan $(86,8 \%)$, berumur antara 17 hingga 24 tahun, pendidikan terakhir SLTA/Sederajat $(90,1 \%)$ dan memperoleh informasi mengenai vaksin Covid-19 dari media massa seperti TV, koran dan lain-lain dan media sosial seperti Instagram, Twitter, Facebook dan lain-lain $(47,3 \%)$. Karakteristik demografi responden secara lengkap disajikan pada Tabel 1.

Tabel 1. Karakteristik demografi responden $(n=91)$

\begin{tabular}{|c|c|c|c|}
\hline & Karakteristik & Frekuensi & Persentase $(\%)$ \\
\hline \multirow[t]{2}{*}{ Jenis Kelamin } & Perempuan & 79 & 86,8 \\
\hline & Laki-laki & 12 & 13,2 \\
\hline Umur (tahun) & & \multicolumn{2}{|c|}{ Min-Max: 17-24 } \\
\hline \multirow[t]{3}{*}{ Pendidikan Terakhir } & SLTA/Sederajat & 82 & 90,1 \\
\hline & D3/Sederajat & 2 & 2,2 \\
\hline & S1/Sederajat & 7 & 7,7 \\
\hline \multirow[t]{4}{*}{ Pengeluaran Keluarga } & < Rp. 1.416 .000 & 25 & 27,5 \\
\hline & Rp. $1.416 .001-2.128 .000$ & 36 & 39,6 \\
\hline & Rp. $2.128 .001-4.800 .000$ & 20 & 22,0 \\
\hline & Rp. 4.800.001-24.000.000 & 10 & 11,0 \\
\hline \multirow[t]{2}{*}{ Status Menikah } & Sendiri (Belum menikah/cerai) & 91 & 100 \\
\hline & Menikah & 0 & 0 \\
\hline \multirow[t]{3}{*}{ Agama } & Islam & 32 & 35,2 \\
\hline & Katolik & 15 & 16,5 \\
\hline & Kristen & 44 & 48,4 \\
\hline \multirow[t]{2}{*}{ Status Bekerja } & Bekerja & 3 & 3,3 \\
\hline & Tidak Bekerja & 88 & 96,7 \\
\hline \multirow[t]{2}{*}{ Kepemilikan Asuransi } & BPJS & 59 & 64,8 \\
\hline & Tidak Ada & 32 & 35,2 \\
\hline \multirow[t]{6}{*}{ Sumber Informasi Tentang Covid-19 } & $\begin{array}{l}\text { Media massa seperti TV, Koran, dll dan Media sosial } \\
\text { seperti Instagram, Twitter, Facebook, dll. }\end{array}$ & 43 & 47,3 \\
\hline & Webinar online & 13 & 14,3 \\
\hline & Jurnal atau artikel ilmiah & 3 & 3,3 \\
\hline & Informasi/ update dari organisasi profesi & 0 & 0 \\
\hline & $\begin{array}{l}\text { Informasi Update dari Kementerian Kesehatan/ Satgas } \\
\text { Covid-19 }\end{array}$ & 32 & 35,2 \\
\hline & Lainnya & 0 & 0 \\
\hline \multirow{2}{*}{$\begin{array}{l}\text { Keluarga, sahabat, rekan kerja atau } \\
\text { diri sendiri pernah terkena Covid-19 }\end{array}$} & Pernah & 26 & 28,6 \\
\hline & Tidak pernah & 65 & 71,4 \\
\hline
\end{tabular}


Daniel Ginting et al., Survei Cross-Sectional Online Untuk Menilai Vaksin Covid-19 Terkait Akseptabilitas, Pengetahuan dan Kesediaan Membayar di Kalangan Mahasiswa Kesehatan Masyarakat di Provinsi Sumatera Utara

\section{Akseptabilitas Vaksin Covid-19}

Mayoritas responden $(53,8 \%)$ tidak bersedia untuk menerima vaksin Covid-19. Akseptabilitas vaksin Covid-19 secara lengkap disajikan pada Gambar 1.

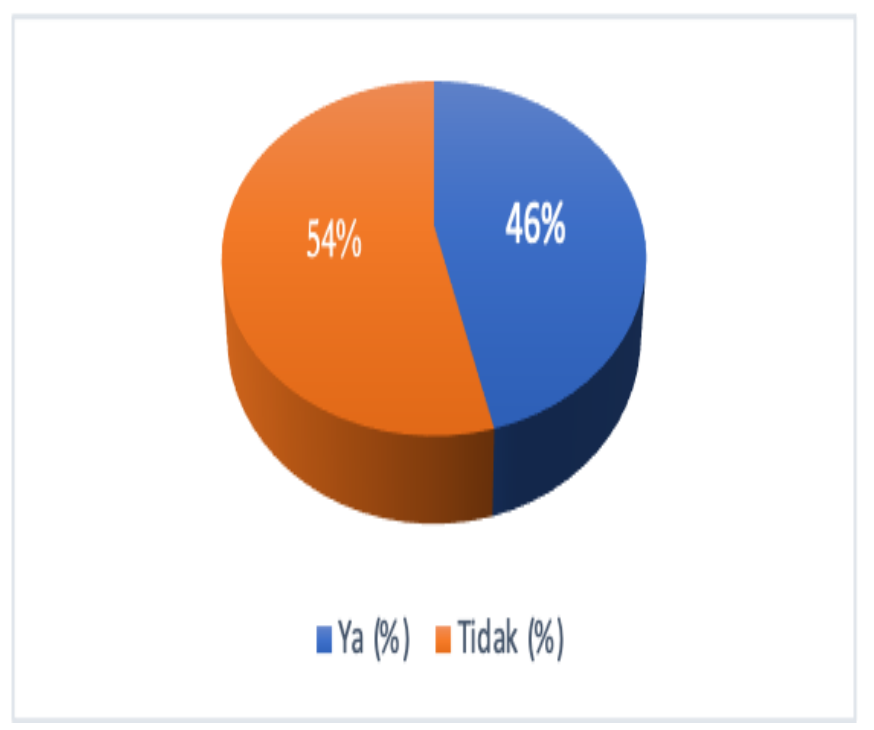

Gambar 1. Akseptabilitas vaksin Covid19

\section{Pengetahuan Vaksin Covid-19}

Tabel 2 mendiskripsikan pengetahuan vaksin covid-19, 51,6\% responden mengatakan bahwa vaksin adalah obat yang dapat membantu menyembuhkan penyakit Covid-19. Mayoritas responden menjawab ia bahwa vaksin Covid-19 yang dapat digunakan di Indonesia harus melewati tahap uji klinik yang harus dilakukan di Indonesia $(96,7 \%)$.

Tabel 2. Pengetahuan vaksin Covid-19 responden $(\mathrm{n}=91)$

\begin{tabular}{|c|c|c|}
\hline Pengetahuan vaksin Covid-19 & Ya $(\%)$ & Tidak (\%) \\
\hline $\begin{array}{l}\text { (P1) Vaksin adalah obat yang } \\
\text { dapat } \\
\text { menyembuhkan } \\
\text { penyantu }\end{array}$ & 51,6 & 48,4 \\
\hline
\end{tabular}

(P2) Vaksin Covid-19 yang dapat digunakan di Indonesia harus melewati tahap uji klinik yang harus dilakukan di Indonesia

(P3) Sasaran vaksinasi Covid-19 di Indonesia adalah populasi berusia 18-59 tahun

(P4) Vaksin Covid-19 yang saat ini dapat digunakan di Indonesia telah mendapatkan izin UEA dan BPOM dengan nilai efikasi $70 \%$

96,7

95,6

4,4

95,6

4,4

(P5) Penerimaan vaksinasi Covid19 di Indonesia dilakukan secara bertahap diawali dari tenaga kesehatan, pelayanan publik dan populasi umum
(P6) Efek samping yang dapat

terjadi dari vaksin Covid-19 antara lain mual, pusing, demam dan mengantuk.

(P7) Kelompok masyarakat yang memiliki penyakit penyerta, pernah menderita Covid-19 dan ibu menyusui tetap dapat menjadi sasaran penerima vaksin Covid-19 yang saat ini digunakan.

Vaksin Covid-19 yang saat ini dapat digunakan di Indonesia telah mendapat izin UEA dan BPOM dengan nilai efikasi $70 \%$. Mayoritas responden $(85,7 \%)$ menjawab ia terhadap efek samping yang dapat terjadi dari vaksin Covid-19 antara lain mual, pusing, demam dan mengantuk.

\section{Kesediaan Membayar Vaksin Covid-19}

Mayoritas responden tidak bersedia untuk membayar vaksin Covid-19 (53,8\%). Kesediaan membayar vaksin Covid-19 secara lengkap disajikan pada Gambar 2.

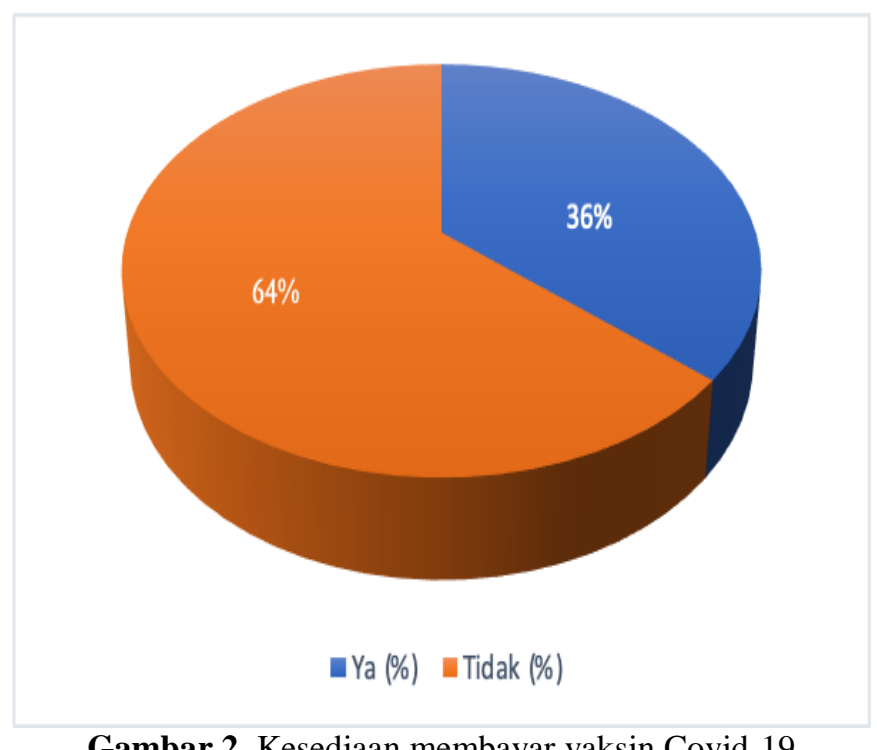

Gambar 2. Kesediaan membayar vaksin Covid-19

\section{Alasan tidak mau divaksin Covid-19}

Mayoritas responden tidak mau divaksin karena takut efek samping $(13,2 \%)$, belum siap/ ragu $(12,1 \%)$ dan takut disuntik (8,8\%). Alasan lengkap responden tidak mau divaksin disajikan pada Tabel 3. Hasil analisis statistik hubungan antara pengetahuan dan kesediaan membayar vaksin Covid-19 dengan akseptabilitas vaksin Covid-19 pada mahasiswa kesehatan masyarakat (Tabel 4) diperoleh bahwa ada hubungan yang signifikan antara kesediaan membayar dengan akseptabilitas vaksin Covid-19 (p-value <0,05), sedangakan uji statistik menunjukkan tidak ada hubungan pengetahuan dengan akseptabilitas vaksin Covid-19 (p-value >0,05). 
Daniel Ginting et al., Survei Cross-Sectional Online Untuk Menilai Vaksin Covid-19 Terkait Akseptabilitas, Pengetahuan dan Kesediaan Membayar di Kalangan Mahasiswa Kesehatan Masyarakat di Provinsi Sumatera Utara

Tabel 3. Alasan tidak mau divaksin Covid-19 $(\mathrm{n}=91)$

\begin{tabular}{lcc}
\hline \multicolumn{1}{c}{$\begin{array}{c}\text { Alasan tidak bersedia } \\
\text { divaksin Covid-19 }\end{array}$} & Ya $(\%)$ & Tidak $(\%)$ \\
\hline Tidak yakin keamanan & 7 & 7,7 \\
Tidak yakin efektivitas & 3 & 3,3 \\
Takut efek samping & 12 & 13,2 \\
Tidak percaya vaksin & 1 & 1,1 \\
Kepercayaan/ agama & 1 & 1,1 \\
Belum siap/ragu & 11 & 12,1 \\
Takut di suntik & 8 & 8,8 \\
Tidak diizinkan keluarga & 3 & 3,3 \\
Menunggu pilihan vaksin & 1 & 1,1 \\
lainnya & & \\
Lainnya & 2 & 2,2 \\
\hline
\end{tabular}

Tabel 4. Hubungan pengetahuan tentang vaksin Cobid-19 dan kesediaan membayar dengan akseptabilitas vaksin Covid-19

\begin{tabular}{ccccc}
\hline Kode Pertanyaan & Pilihan & $(1)$ & $(2)$ & p-value \\
\hline P1 & Ya & 42,6 & 57,4 & $>0,05$ \\
& Tidak & 50,0 & 50,0 & \\
P2 & Ya & 47,7 & 52,3 & $>0,05$ \\
& Tidak & 0,0 & 100 & \\
P3 & Ya & 46,0 & 54,0 & $>0,05$ \\
& Tidak & 50,0 & 50,0 & \\
P4 & Ya & 46,0 & 54,0 & $>0,05$ \\
& Tidak & 50,0 & 50,0 & \\
P5 & Ya & 47,2 & 52,8 & $>0,05$ \\
& Tidak & 0,0 & 100 & \\
P6 & Ya & 46,2 & 53,8 & $>0,05$ \\
& Tidak & 46,2 & 53,8 & \\
P7 & Ya & 46,6 & 53,4 & $>0,05$ \\
& Tidak & 44,4 & 55,6 & \\
Kemauan & Ya & 66,7 & 33,3 & $<0,05$ \\
membayar & Tidak & 34,5 & 65,5 & \\
\hline
\end{tabular}

(1): bersedia ikut vaksinasi Covid-19(\%)

(2): tidak bersedia ikut vaksinasi Covid-19 (\%)

\section{Pembahasan}

Fokus global dalam penanganan pandemik Covid19 adalah menurunkan laju penularan dengan peningkatan cakupan vaksinasi Covid-19. Studi ini berfokus untuk menilai vaksin Covid-19 terkait akseptabilitas, pengetahuan dan kesediaan membayar di kalangan mahasiswa kesehatan masyarakat di Provinsi Sumatera Utara.

Studi ini menemukan bahwa 54\% mahasiswa kesehatan masyarakat di Provinsi Sumatera Utara tidak bersedia menerima vaksin Covid-19 karena takut efek samping $(13,2 \%)$, belum siap/ragu $(12,1 \%)$ dan takut disuntik $(8,8 \%)$. Hal yang sama diungkapkan studi penerimaan vaksin Covid-19 di Finlandia bahwa kekhawatiran efek samping adalah alasan utama penolakan vaksin Covid-19 di Finlandia (Hammer et al., 2021).

Sebesar $63,7 \%$ mahasiswa kesehatan masyarakat di Provinsi Sumatera Utara juga tidak bersedia membayar vaksin Covid-19. Uji statistik menunjukkan tidak ada hubungan pengetahuan dengan akseptabilitas vaksin Covid-19 di kalangan mahasiswa kesehatan masyarakat. Studi penerimaan vaksin di Taiwan menyatakan penduduk yang berpendidikan setingkat universitas memiliki kemauan yang lebih rendah untuk divaksin Covid-19 (Tsai et al., 2021). Penemuan lain menyebutkan penerimaan vaksin Covid-19 sangat dipengaruhi oleh sebera efektif vaksin dapat menghambat penyakit akibat Covid-19 (Lu et al., 2021) dan kemauan untuk melindungi orang lain dari Covid-19 (Machida et al., 2021).

Survei pengetahuan vaksin Covid-19 di kalangan mahasiswa kesehatan masyarakat dalam studi ini menemukan bahwa sebagian besar mahasiswa menganggap vaksin adalah obat yang dapat membantu menyembuhkan penyakit Covid-19. Vaksin bukanlah obat. Vaksin mendorong pembentukan kekebalan spesifik pada penyakit Covid-19 agar terhindar dari tertular ataupun kemungkinan sakit berat (Kemenkes, 2020). Pendidikan kesehatan oleh ahli kesehatan masyarakat sangat diperlukan untuk meluruskan pengetahuan mahasiswa kesehatan masyarakat tentang vaksin Covid-19. Studi di Ekuador menyarankan peningkatan kampanye pendidikan vaksin Covid-19 untuk meningkatkan pengetahuan penduduk tentang vaksin Covid-19 agar kepercayaan terhadap vaksin meningkat dan meningkatkan penerimaan terhadap vaksin Covid-19 (Jaramillo-Monge et al., 2021).

Sebanyak $64 \%$ mahasiswa kesehatan masyarakat dalam studi ini tidak bersedia membayar vaksin Covid19. Uji statistik menunjukkan ada hubungan signifikan antara kesediaan membayar dengan akseptabilitas vaksin Covid-19. Hal ini menunjukkan bahwa vaksin gratis dari pemerintah sangat menentukan tingkat cakupan vaksinasi Covid-19 di kalangan mahasiswa kesehatan masyarakat. Studi di Jepang menunjukkan penerimaan vaksin Covid-19 lebih rendah pada masyarakat berpenghasilan rendah (Machida et al., 2021). Pengeluaran keluarga mahasiswa kesehatan masyarakat dalam studi ini mayoritas berkisar Rp.1.416.001 - Rp. 2.128.000 (menengah kebawah). Kesediaan membayar vaksin Covid-19 terendah (22\%) di antara responden yang tergolong kelas miskin dan yang tertinggi (74\%) di antara responden yang tergolong kelas atas. Kesediaan membayar berangsur meningkat sesuai status ekonomi. Kesediaan membayar juga lebih tinggi pada kelompok usia $>65$ tahun dibanding dengan kelompok usia yang lebih muda (Kementerian Kesehatan Republik Indonesia et al., 2020).

\section{SIMPULAN}

Hasil studi ini menyimpulkan bahwa akseptabilitas vaksin Covid-19 di kalangan mahasiswa kesehatan masyarakat di Provinsi Sumatera Utara masih rendah demikian juga pengetahuan dan kesediaan membayar. Tidak ada hubungan pengetahuan dengan akseptabilitas vaksin Covid-19. Mayoritas mahasiwa kesehatan masyarakat menganggap vaksin adalah obat untuk penyakit Covid-19. Ada hubungan yang signifikan antara kesediaan membayar dengan akseptabilitas vaksin 
Daniel Ginting et al., Survei Cross-Sectional Online Untuk Menilai Vaksin Covid-19 Terkait Akseptabilitas, Pengetahuan dan Kesediaan Membayar di Kalangan Mahasiswa Kesehatan Masyarakat di Provinsi Sumatera Utara

Covid-19 di kalangan mahasiswa kesehatan masyarakat, sehingga program vaksin gratis sangat menentukan tingkat cakupan vaksinasi Covid-19 pada mahasiswa kesehatan masyarakat. Intervensi kampanye pendidikan kesehatan tentang vaksin Covid-19 dari ahli kesehatan masyarakat sangat diperlukan guna meluruskan pengetahuan vaksin Covid-19 mahasiswa kesehatan masyarakat yang akhirnya diharapkan mampu membangun kepercayaan terhadap efekstivitas vaksin Covid-19.

\section{DAFTAR PUSTAKA}

Bono, S. A., Villela, E. F. de M., Siau, C. S., Chen, W. S., Pengpid, S., Hasan, M. T., Sessou, P., Ditekemena, J. D., Amodan, B. O., Hosseinipour, M. C., Dolo, H., Fodjo, J. N. S., Low, W. Y., \& Colebunders, R. (2021). Factors affecting COVID-19 vaccine acceptance: an international survey among low-and middle-income countries. Vaccines, 9(5), 1-20. https://doi.org/10.3390/vaccines9050515

Flacco, M. E., Soldato, G., Martellucci, C. A., Carota, R., Di Luzio, R., Caponetti, A., \& Manzoli, L. (2021). Interim estimates of covid-19 vaccine effectiveness in a mass vaccination setting: Data from an italian province. Vaccines, 9(6), 1-12. https://doi.org/10.3390/vaccines 9060628

Hammer, H. C., Cristea, V., Dub, T., \& Sivelä, J. (2021). Erratum: High but slightly declining COVID-19 vaccine acceptance and reasons for vaccine acceptance, Finland April to December 2020Corrigendum (Epidemiology and infection (2021) 149 (e123)). Epidemiology and Infection, 149(December 2020), e133. https://doi.org/10.1017/S0950268821001217

Jaklevic, M. C. (2020). Flu Vaccination Urged during COVID-19 Pandemic. JAMA - Journal of the American Medical Association, 324(10), 926-927. https://doi.org/10.1001/jama.2020.15444

Jaramillo-Monge, J., Obimpeh, M., Vega, B., Acurio, D., Boven, A., Verhoeven, V., \& Colebunders, R. (2021). Covid-19 vaccine acceptance in azuay province, ecuador: A cross-sectional online survey. Vaccines, 9(6), 1-11. https://doi.org/10.3390/vaccines9060678

Kemenkes. (2020). Buku Saku.Pdf. https://dinkes.jatimprov.go.id/userimage/dokumen /Buku Saku.pdf

Kemenkes RI. (2021). Vaksinasi COVID-19 Nasional. https://vaksin.kemkes.go.id/\#/vaccines

Kementerian Kesehatan Republik Indonesia, ITAGI, WHO, \& UNICEF. (2020). Survei Penerimaan Vaksin COVID-19 di Indonesia. Satuan Gugus Tugas Penanganan COVID-19, November, 1-26.

Lu, J., Wen, X., Guo, Q., Ji, M., Zhang, F., Wagner, A. L., \& Lu, Y. (2021). Sensitivity to covid-19 vaccine effectiveness and safety in shanghai, china. $\quad$ Vaccines, $\quad 9(5), \quad 1-9$. https://doi.org/10.3390/vaccines9050472

Machida, M., Nakamura, I., Kojima, T., Saito, R., Nakaya, T., Hanibuchi, T., Takamiya, T., Odagiri, Y., Fukushima, N., Kikuchi, H., Amagasa, S., Watanabe, H., \& Inoue, S. (2021). Acceptance of a covid-19 vaccine in japan during the covid-19 pandemic. Vaccines, 9(3), 1-11. https://doi.org/10.3390/vaccines9030210

Mesele, M. (2021). Covid-19 vaccination acceptance and its associated factors in sodo town, wolaita zone, southern ethiopia: Cross-sectional study. Infection and Drug Resistance, 14, 2361-2367. https://doi.org/10.2147/IDR.S320771

Tavolacci, M. P., Dechelotte, P., \& Ladner, J. (2021). Covid-19 vaccine acceptance, hesitancy, and resistancy among university students in france. Vaccines, 9(6), 1-14. https://doi.org/10.3390/vaccines9060654

Tsai, F. J., Yang, H. W., Lin, C. P., \& Liu, J. Z. (2021). Acceptability of covid-19 vaccines and protective behavior among adults in taiwan: Associations between risk perception and willingness to vaccinate against covid-19. International Journal of Environmental Research and Public Health, 18(11). https://doi.org/10.3390/ijerph18115579

Worldometer. (2021). Worldometers Covid Live Update. Https://Www.Worldometers.Info > Coronavirus. 